\title{
Intellectual Property and Horticultural Science: The Path from Idea, Technology Development, Commercialization, and Impact
}

\author{
John R. Clark \\ Department of Horticulture, 316 Plant Science, University of Arkansas, Fayetteville, AR 72701
}

\begin{abstract}
Most of us who work in the area of research and development in horticultural science begin our investigations from an idea or inspiration, and develop a plan to research this idea. How we might develop the idea depends on a number of factors, which could include funding, equipment and facilities, interest by growers or industry in the potential output, interest and talents of coworkers and graduate students, and progress in the line of investigation. We might work on the idea for a short while or an entire career.

For those who work in horticultural science research in the public sector, traditionally our technology has been shared freely with the public, mainly because of our publicly funded history of the Morrill Act passed by the U.S. Congress in 1862 that began the land-grant university system coupled with the Hatch Act passed in 1886 that established the agricultural experiment stations in each state. Also, the publicly funded U.S. Department of Agriculture-Agricultural Research Service has contributed greatly to our horticultural science legacy in the United States. This concept of "freely shared" technology was absolute or at least dominant up until a few decades ago.
\end{abstract}

One area of research and development that began to use intellectual property protection (IPR) for research products some years back was plant breeding. However, this was a rather slow development. From personal experience, I have enjoyed hearing my predecessor and former ASHS President and ASHS Hall of Fame inductee James N. Moore (Distinguished Professor Emeritus, University of Arkansas) tell the story of a discussion of plant breeders and the topic of protecting plant cultivars sometime in the late 1960s and 1970s, and how poorly he and his peers viewed the entire IPR concept; they thought it was a bad idea and wanted nothing to do with it. However, as time went on, Dr. Moore shifted his perspective on patenting his fruit cultivars in the early to mid-1980s, primarily as a result of the awareness that others outside his Arkansas grower clientele were benefitting from his achievements coupled with reduced funding in the areas of federal Hatch Act formula funds and state support. He simply thought that plant patenting and payment of royalties might develop into an avenue to help support the continu-

Introduction to Feature article "Scientific Basis of a Unique Formulation for Reducing Sunburn of Fruits," by Larry E. Schrader. ance of his breeding program. That has in fact come about in the last 25 years.

There are many other stories of protected plant cultivars and their successes in recent years. From a personal perspective, I have never experienced reduced use of any cultivars that have been released from Dr. Moore's or my program as a result of the small plant royalty charged. At least at the royalty level of these cultivars, decisions on cultivar use are based on the cultivar's merits, not on an added "cost" perceived or not by the buyer of the plants. This is at least one instance in which growers or end-users are willing to ante up to support the research effort and its substantial costs.

Another perspective I have developed over the last 10 years or so is an awareness of the impact of technology development. Many of us, and this certainly includes me, began our research careers focused on a few key areas of scholarship. First among these was publishing refereed journal articles and, to varying degrees, attainment of extramural funding. This may not be the best thing to admit, but my first years as a researcher were geared toward researching ideas that could be completed fairly quickly and yield a journal article. It was always thought that if a grower or others could use the technology developed, that would be great. However, it was not required that it be used, and less energy was often placed on its implementation or use than on development. A key reason was that the value of the research was measured in scholarship achievement (i.e., the refereed article) and possibly the grant funding that provided the support for the research.

A couple of issues came on my horizon a few years back. One such issue, after promotion and tenure were achieved, plus getting older, wiser, and understanding that immortality was a notion of youth, was the desire to more strongly focus on research that made a difference. Second was the idea of impact measured by my boss. I first heard of writing an "impact statement" 8 or 10 years ago. I thought it was another make-work item dreamed up by administrators. I nearly refused to write the statements; as it turned out, I was not brave enough to defy the leadership that wanted these. I wrote one or more of these each year, still not sure of the value. However, in more recent years, I have heard more and more about "impact" and, in working with the ASHS National Issues Task Force and our contacts in Washington, DC, have learned that "impact" is likely a key component of our survival as publicly funded horticultural scientists. Our funding agencies want to see an application or use of the technology they fund! This led me to the idea that research best lead to something identifiably of value, and this best be communicated and validated in some way-simply put: the impact. I then realized another value of intellectual property rights in the fruit breeding program I directed-I had records of all legally propagated plants of the cultivars from the program. I had a simple way of stating value of plants sold and their approximate impact to growers and others! A protected technology was also a measured-impact technology. Thus, a value of IPR was not simply program support, but a quite good method of judging impact, at least from a direct program product level.

In 2004, I had the honor of serving on a review team of the Washington State University (WSU) Tree Fruit Breeding Program; my main area of responsibility was in the IPR aspects of the program. Although not part of the breeding effort, Dr. Larry Schrader (based at the WSU Tree Fruit Research \& Extension Center, Wenatchee) and I visited during my time in eastern Washington, and he told me of his work in the development of a sunburn protectant for apples. I was intrigued with his story and particularly enjoyed his enthusiasm and wisdom surrounding his research. Our conversation was brought about because Dr. Schrader had developed proprietary technology that WSU was protecting through a utility patent and he shared some experiences in this IPR endeavor. Dr. Schrader outlined what he had worked on for a number of years, some of the successes in this area of research, and that he and his team's invention should make a substantial impact on reducing sunburn damage in commercial apple production. He was quite clear that this technology development was a good example of a long-term research investment that should culminate with patented technology that would be introduced and marketed by a private entity.

The following feature article in this issue describes Dr. Schrader's work. Schrader identified a disorder (i.e., sunburn) that was costing apple growers hundreds of millions of dollars annually. He conducted research to identify the causes of the disorder, conceived a concept for a sprayable formulation that would protect apples from sunburn, invented the formulation, and demonstrated its efficacy. A patent was obtained on the intellectual property (i.e., formulation) by WSU; a startup company (i.e., FruitGard, LLC) was formed by Schrader to license the intellectual 
property; and a larger company (i.e., Pace International, LLC) partnered with FruitGard, LLC to manufacture and distribute the product worldwide. This feature article presents the conceptual basis, invention, and testing of efficacy for this product, called RAYNOX®.

This article exemplifies the success of a scientist at a public institution who started with a problem; identified a possible solution; and then followed through to invent, patent, and help commercialize that solution.
Intellectual property is developed daily in our public institutions, but much of it never reaches the marketplace. Many academic scientists do not want to spend their time seeking patent protection or commercializing a product. Failure to do so, however, disallows universities and inventors of the royalties that could be collected for their research efforts. In an era of shrinking budgets at public institutions, patenting and commercialization of our intellectual property can provide an important income stream and reflect the impact of the technology. Moreover, commercialization of this intellectual property will benefit the agricultural industries we serve by providing new technologies to help them remain competitive in an international marketplace. Consumers will be the ultimate beneficiary of these technologies as higher quality produce will be available. I imagine there are a number of other horticultural scientists with ideas in various levels of technology development; this article will serve to inspire you toward unbridled success. 